\title{
Role of Anti Angiogenic Therapy in Prevention of Recurrence in Hormonal Positive Breast Cancer: A Secondary Prevention Strategy and Method of Therapy
}

\author{
M. A. Nezami*, Jessica Garner \\ Pacific Medical Center of Hope, Fresno, CA, USA \\ Email:*amnezami@yahoo.com
}

How to cite this paper: Nezami, M.A. and Garner, J. (2017) Role of Anti Angiogenic Therapy in Prevention of Recurrence in Hormonal Positive Breast Cancer: A Secondary Prevention Strategy and Method of Therapy. Journal of Cancer Therapy, 8 , 546-552.

https://doi.org/10.4236/jct.2017.86046

Received: April 25, 2017

Accepted: June 17, 2017

Published: June 20, 2017

Copyright $\odot 2017$ by authors and Scientific Research Publishing Inc. This work is licensed under the Creative Commons Attribution International License (CC BY 4.0).

http://creativecommons.org/licenses/by/4.0/

\begin{abstract}
Existing literature supports the role of signaling protein vascular endothelial growth factor (VEGF) in tumor growth and metastasis and furthers its involvement in recurrence. In both experimental and clinical studies, VEGF has been shown to be a significant factor involved for aberrant blood vessel growth, and in fact is the target of several classes of antineoplastic drugs [1] [2] [3] [4]. That said, the current standard of care for estrogen receptor positive breast cancer (although improved over the last decade), has not provided a "meaningful preventive shift" since the discovery of angiogenesis and its role in induction of recurrence. In this article, we discuss an anti angiogenic therapy implementing natural compounds to inhibit the production of VEGF. We applied our preclinical data to justify the predicted effect on VEGF. We used liquid biopsy to monitor patients response to therapy as a surrogate for recurrence. We hypothesize that by inhibition of angiogenesis through this protocol, we are able to positively impact tumor recurrence. It is our experience that patients in our sample even with high recurrence scores (based on Oncotype Dx testing) had a major reduction in recurrence when estrogen blockers were combined with this protocol. We also propose longitudinal studies to compare outcomes with combinational therapies with estrogen blockers in highly expected to recur disease.
\end{abstract}

\section{Keywords}

Anti Angiogenic Therapy, Breast Cancer, Prevention Strategy

\section{Introduction}

Invasive breast cancer is a disease that affects 1 in every 8 women [5]. Despite 
advances in screening tools and early intervention, it remains a common deadly disease, with many women experiencing progression or metastatic disease despite our best efforts at treatment. Although a few screening tools exist to determine who is at risk of recurrence, overall the molecular dynamics are still poorly understood [6]. It is also well described in the literature that angiogenesis plays an important role in hormonal resistance and further tumor recurrence in cases of previously treated breast carcinoma [7] [8] [9] [10] [11]. This understanding has suggested the use of angiogenic blockers as "preventive" therapies to be considered in early stages disease management. Unfortunately, these drugs' side effects, and lack of longitudinal studies to support their application as prophylactic strategy, have been a barrier for their use in this fashion.

\section{Methods and Materials}

15 cases of Stage I-III breast cancer patients in whom tumors were estrogen receptor (ER) positive were randomly selected, and their biological cancer markers were assessed prior to, and after intervention. Most patients had undergone lumpectomy or mastectomy, and started hormonal blockade prior to the intervention. None of these patients received neoadjuvant chemotherapy or radiation.

Hormonal blockade was defined by intake of tamoxifen (dosed at least $10 \mathrm{mg}$ per day, all had extensive metabolizer profile identified), or an aromatase inhibitor of physician's choice. Several of these patients' breast cancer assays performed by Oncotype Dx, and were given high recurrence scores (however, none of these patients chose to receive chemotherapy). The maximum Oncotype Dx score was reported at 50\%. A liquid biopsy (circulating tumor DNA) was obtained when available. These were obtained prior to therapy, and performed again after therapy.

The antiangiogenic therapy was introduced by intravenous injections of a polyphenols including Quercetin, per multitargeted epigenetic therapy (MTET) protocol. The patients' tumor markers, (such as CA 15-3 and CA 27.29), along with growth factors, and serum/plasma VEGF were monitored before, during, and after therapy. The hormonal blockade drug of choice in each patient was not changed. These patients did not receive any other mode of therapy, and were instructed not to change their diet or lifestyle.

\section{Results}

100 percent of patients had reduced and/or normalized growth factors following treatment with the MTET protocol. These markers included fibroblast growth factor 2 (FGF-2), insulin-like growth factors 1 (IGF-1) and VEGF. In cases where liquid biopsy was available, there was complete resolution of circulating tumor DNA (ctDNA) post-therapy. There was direct correlation between the frequency of therapy and reduction in the biomarkers, specifically serum/plasma VEGF. The frequency of therapy was determined by elevations in these biomarkers prior to administration of the therapy. Patients with dramatically ele- 
vated biomarkers had treatment as often as ten treatments in a two-week period, while those slightly abnormal biomarkers were given treatment as infrequently as once a month. Since every individual's biomarkers were measured and reported abnormal prior to therapy, every case represented their own control. There were no side effects reported from the therapy. None of the patients were found to have recurrence over the monitoring time, which so far has been between 6 months to 5 years. Here we include a case, with a summary of the results.

\section{Case Study}

A 68-year-old female with a history of left lobular invasive breast cancer, presented to our clinic treatment. She was first diagnosed in June 2016, and was status post biopsy of the left breast. The pathology showed ER and progesterone receptor (PR) positive, human epidermal growth factor receptor 2 (HER2) negative. A PET scan was done for staging, which was negative for distant metastasis. She had a remote history of thyroid carcinoma insitu, and was status-post thyroidectomy. She also had a history of laryngeal squamous cell carcinomain 2011, status-post radiation and cetuximab, which she responded to.

She was referred to us for second opinion, and was evaluated through BioFocus labs for circulating tumor cells (CTCs), Guardant 360 for ctDNA, and Caris Target Now for molecular profiling. Her molecular profiling revealed several mutations, including somatic mutations at BRCA (breast cancer susceptibility gene), CDH1 (cadherin-1), CSF1R (colony stimulating factor 1 receptor), IDH1 (Isocitrate dehydrogenase 1), and PI3k (phosphoinositide 3-Kinase) were detected by these labs. A BRCA germ line test was ordered and it came back negative. Tumor markers were drawn through LabCorp and were reported normal, although her serum HER2 was borderline normal at $14(\mathrm{ng} / \mathrm{mL})$. The CTC was also negative. Her ctDNA was positive for BRAF, AR, FGFR, and ERBB2.

She was started on Tamoxifen at $10 \mathrm{mg}$ per day, as her Cytochrome P450 2D6showed an extensive metabolizer profile. She was started on daily IV epigenetic therapies (MTET protocol), which she received for 10 days over a two week period. Her serum Her2/Neu Quant level dropped from $14.6 \mathrm{ng} / \mathrm{mL}$ down to $11.7 \mathrm{ng} / \mathrm{mL}$, post therapy. After 10 treatments, second ctDNA assay showed marked reduction of the mutant allele fraction (MAF), (see Figure 1), which AR and BRAF no longer detected, andFGF2 at $0.1 \%$. The total MAF dropped from $1.4 \%$ down to $0.1 \%$. The patient underwent mastectomy in August 2016. The surgical pathologyrevealed one of eleven lymph nodes positive, with positive lymphovascular invasion, and negative skin involvement. At that point, she was staged T3N1M0, with moderately differentiated lobular carcinoma. Her guardant was repeated post-mastectomy, which showed and increased in ctDNA. ERBB2, PI3k and ARID1, were detected, with a MAF of $0.8 \%$. This increased prompted us to start the patient back on IV therapy with MTET protocol. Following treatment, her ctDNA was repeated in October 2016, and was found nondetectable. 


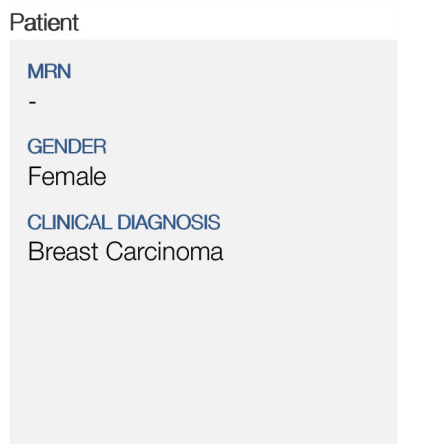

Reporting
REPORT DATE
APR-21-2017
RECEIPT DATE
APR-14-2017
COLECTION DATE
APR-13-2017
SPECIMEN
Blood

Physician

NAME

Mohammad Amin Nezami

ACCOUNT

Orange Coast Medical Center of Hope

496 Old Newport Blvd Ste 7, Newport Beach, CA 92663

PHONE

(949) 515-4673

FAX

ADDITIONAL RECIPIENT

Guardant360 Tumor Response Map

The Guardant360 Tumor Response Map illustrates the mutant allele percentage (\% cfDNA) of observed somatic variants at each sample submission time point. The "Somatic Alteration Burden" value below refers to the maximum \% cfDNA detected at each time point. Amplifications are not plotted, and only the first and last four test dates are plotted. Please see the Physician Portal (https://portal.guardanthealth.com) for the Tumor Response Map with all test dates.

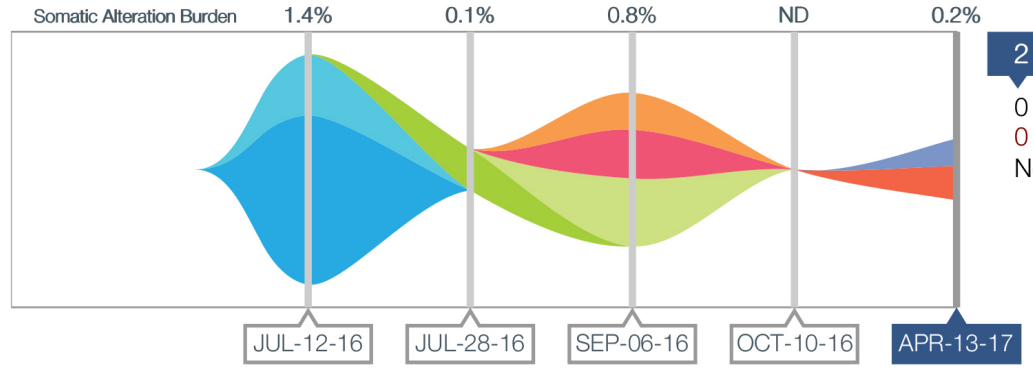

Somatic Alterations: Not Detected (ND). Somatic alterations may be present that are below the limit of detection of this test. Certain sample or variant characteristics may result in reduced analytic sensitivity. The absence of detectable somatic alterations in circulating cell-free DNA does not preclude the presence of somatic alterations in the tumor.

Summary of Somatic Alterations \& Associated Treatment Options

The percentage of altered cell-free DNA (\% cfDNA) circulating in blood is related to the unique tumor biology of each patient. Factors that may affect the \% cfDNA of detected somatic alterations include tumor growth, turn-over, size, heterogeneity, vascularization, disease progression, and treatment.

\begin{tabular}{|c|c|c|c|c|c|}
\hline \multirow[t]{2}{*}{ Alteration } & \multirow[t]{2}{*}{ Mutation Trend } & \multirow[t]{2}{*}{$\begin{array}{l}\% \text { cfDNA or } \\
\text { Amplification }\end{array}$} & $\begin{array}{l}\text { FDA Approved in } \\
\text { Indication }\end{array}$ & $\begin{array}{l}\text { Available for Use in } \\
\text { Other Indications }\end{array}$ & Clinical Drug Trials \\
\hline & & & see page 3 & see page 3 & see page 5 \\
\hline
\end{tabular}

Relevant for Therapy Selection

No tumor alterations associated with known Therapy Selection were detected in this sample.

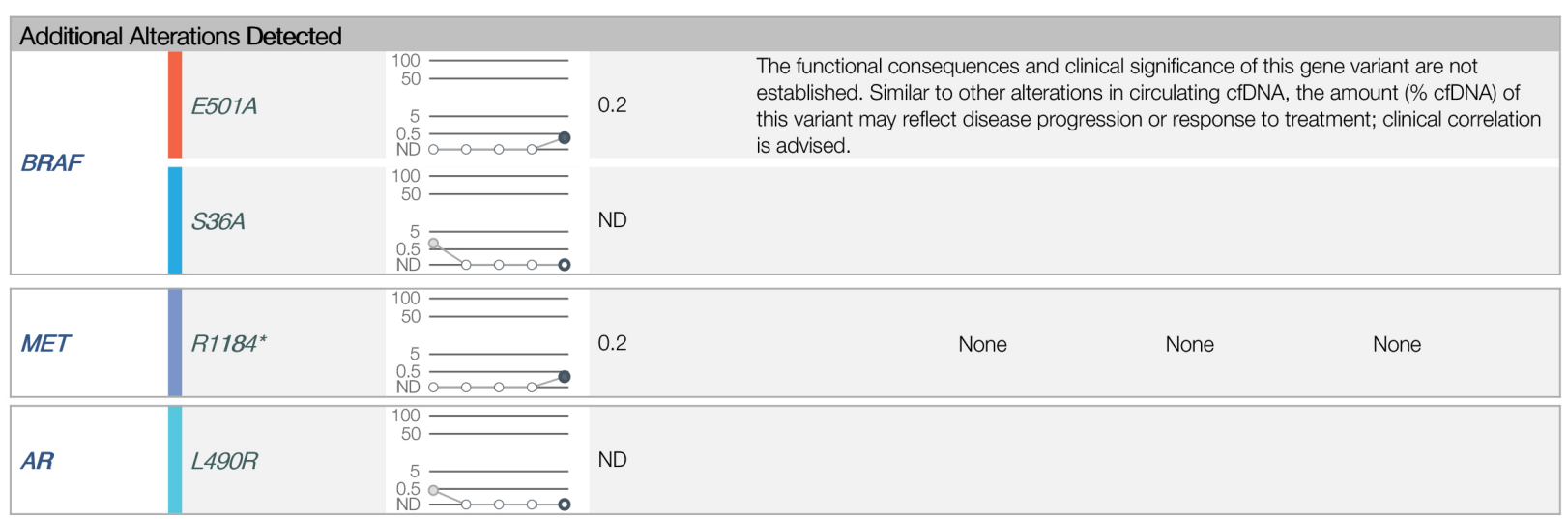

GUARDANTHEALTH

For a more detailed Guardant360 Patient Report, log onto: https://portal.guardanthealth.com or to set up an account, contact Client Services: 855.698.8887 Arthur Baca, MD PhD Laboratory Director | CLIA ID: 05D2070300 | 505 Penobscot Drive, Redwood City, CA 94063 


\begin{tabular}{|c|c|c|c|c|}
\hline DOB: & $\mathrm{ITe}$ & mber 4 & & Biopsy-Free ${ }^{T M}$ Tumor Sequencing \\
\hline PIКЗСА & $D 549 \mathrm{~N}$ & $\begin{array}{r}100 \\
50 \\
\\
5 \\
0.5 \\
\text { ND }\end{array}$ & ND & \\
\hline ARID1A & D1900N & 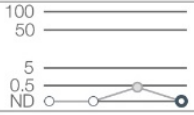 & ND & \\
\hline
\end{tabular}

For a more detailed Guardant360 Patient Report, log onto: https://portal.guardanthealth.com To set up an account, contact Client Services: 855.698 .8887

The chart above annotates the percentage or allele frequency, of altered circulating cell-free DNA (\% cfDNA) detected in this patient. The detected genomic alterations are listed in descending order by $\%$ cfDNA by gene.

The "FDA Approved in Indication" and "Available for Use In Other Indications" columns describe drugs associated with specific genomic alterations. It is based on publicly available information as described in the "Detailed Therapy Results" and "Clinical Relevance of Detected Alterations" sections of the report.

¥ Synonymous mutations and Variants of Uncertain Significance (VUSs): The functional consequences and clinical significance of these alterations are uncertain as is the relevance of therapies targeting these alterations. Similar to other genomic alterations detected in circulating cell-free DNA, the monitoring of these alterations may be reflective of tumor growth, turn-over, size, heterogeneity, vascularization, disease progression, or treatment. This is an area of clinical investigation and the \% cfDNA should be interpreted in context with other clinical criteria and studies.

\section{Definitions}

None.

Comments

Interpretation

Genomic alterations were NOT detected in the circulating cell-free DNA isolated from this patient's blood specimen. The genes listed in Table 1 were analyzed as part of the Guardant360 test, but genomic alterations were not detected in those genes. The types of genomic alterations detected by Guardant 360 include single nucleotide variations, amplifications, fusions in the ALK, FGFR2, FGFR3, RET, ROS1, and NTRK1 genes, and short insertions/duplications/deletions in exons 19 and 20 of theEGFR and ERBB2 genes, and also detects exon 14 skipping of the MET gene. This version of the Guardant 360 test is not validated for the detection of other types of genomic alterations (for example: complex rearrangements, gene deletions, frameshifts, other splice variants or indels other than those specifically listed).

GUARDANT HEALTH ${ }^{\circ} \quad$ Arthur Baca, MD PhD Laboratory Director | CLIA ID: 05D2070300 | 505 Penobscot Drive, Redwood City, CA 94063 T: 855-698-8887 | clientservices@guardanthealth.com | https://portal guardanthealth.com | TST-PRT-001 V14.0|Pg 2 of 4

Figure 1. Marked reduction of the mutant allele fraction (MAF). 
This is an interesting case of successful response in a patient with no detectable distant metastases, but positive ctDNA. This demonstrates the concept of secondary prevention and reduced angiogenesis and heterogeneity of the tumor in response to MTET protocol, which consists of epigenetic therapies, as all ctDNA disappeared with the protocol. It is worth noting that neither tamoxifen nor mastectomy could positively impact the ctDNA, and in fact there was an increase in ctDNA post-mastectomy.

\section{Conclusion}

Our treatment protocol, which uses multitargeted epigenetic therapies, has generated interest in the use of combinational therapy to reduce recurrence, through a safe and effective method of treatment using natural compounds. We believe that such approach could change the current standard of care. Further research is needed to conclude whether this research would translate to improved progression free survival on a large scale, and to determine whether overall survival and cure rates are improved in the setting of hormonally sensitive breast cancer. Further trials are needed to optimize the therapy schedule and protocols.

\section{References}

[1] Ribatti, D., Nico, B., Ruggieri, S., Tamma, R., Simone, G. and Mangia, A. (2016) Angiogenesis and Antiangiogenesis in Triple-Negative Breast cancer. Translational Oncology, 9, 453-457. https://doi.org/10.1016/j.tranon.2016.07.002

[2] Bareschino, M.A., Schettino, C., Colantuoni, G., Rossi, E., Rossi, A., Maione, P. and Gridell, C. (2011) The Role of Antiangiogenetic Agents in the Treatment of Breast Cancer. Current Medicinal Chemistry, 18, 5022-5032. https://doi.org/10.2174/092986711797636072

[3] Coxon, A., Bush, T., Saffran, D., Kaufman, S., Belmontes, B., Rex, K. and Polverino, A. (2009) Broad Antitumor Activity in Breast Cancer Xenografts by Motesanib, a Highly Selective, Oral Inhibitor of Vascular Endothelial Growth Factor, Platelet-Derived Growth Factor, and Kit Receptors. Clinical Cancer Research, 15, 110-118. https://doi.org/10.1158/1078-0432.CCR-08-1155

[4] Heer, K., Kumar, H., Read, J.R., et al. (2001) Serum Vascular Endothelial Growth Factor in Breast Cancer: Its Relation with Cancer Type and Estrogen Receptor Status. Clinical Cancer Research, 7, 3491-3494.

[5] (2017) U.S. Breast Cancer Statistics. http://www.breastcancer.org/symptoms/understand_bc/statistics

[6] Ahmad, A. (2013) Pathways to Breast Cancer Recurrence. ISRN Oncology, 2013, 116. https://doi.org/10.1155/2013/290568

[7] Qu, Z., Ginkel, S.V., Roy, A.M., Westbrook, L., Nasrin, M., Maxuitenko, Y. and Kern, F.G. (2008) Vascular Endothelial Growth Factor Reduces Tamoxifen Efficacy and Promotes Metastatic Colonization and Desmoplasia in Breast Tumors. Cancer Research, 68, 6232-6240. https://doi.org/10.1158/0008-5472.CAN-07-5654

[8] Liu, Y., Tamimi, R.M., Collins, L.C., Schnitt, S.J., Gilmore, H.L., Connolly, J.L. and Colditz, G. A. (2011). The Association between Vascular Endothelial Growth Factor Expression in Invasive Breast Cancer and Survival Varies with Intrinsic Subtypes and Use of Adjuvant Systemic Therapy: Results from the Nurses' Health Study. 
Breast Cancer Research and Treatment, 129, 175-184.

https://doi.org/10.1007/s10549-011-1432-3

[9] Cerezo, A.B., Winterbone, M.S., Moyle, C.W.A., Needs, P.W. and Kroon, P.A. (2015) Molecular Structure-Function Relationship of Dietary Polyphenols for Inhibiting VEGF-Induced VEGFR-2 Activity. Molecular Nutrition \& Food Research, 59, 2119-2131. https://doi.org/10.1002/mnfr.201500407

[10] Reinert, T. and Barrios, C.H. (2015) Optimal Management of Hormone Receptor Positive Metastatic Breast Cancer in 2016. Therapeutic Advances in Medical Oncology, 7, 304-320. https://doi.org/10.1177/1758834015608993

[11] Traina, T.A., Dickler, M.N., Caravelli, J.F., et al. (2005) A Phase II Trial of Letrozole in Combination with Bevacizumab, an Anti-VEGF Antibody, in Patients with Hormone Receptor-Positive Metastatic Breast Cancer. Proceedings from the 2005 San Antontio Breast Cancer Symposium, San Antonio, December 2005.

Submit or recommend next manuscript to SCIRP and we will provide best service for you:

Accepting pre-submission inquiries through Email, Facebook, LinkedIn, Twitter, etc. A wide selection of journals (inclusive of 9 subjects, more than 200 journals)

Providing 24-hour high-quality service

User-friendly online submission system

Fair and swift peer-review system

Efficient typesetting and proofreading procedure

Display of the result of downloads and visits, as well as the number of cited articles

Maximum dissemination of your research work

Submit your manuscript at: http://papersubmission.scirp.org/

Or contact jet@scirp.org 